\title{
The Canadian Association of Gastroenterology Research Committee report: Continued commitment to promoting excellence in gastrointestinal related research
}

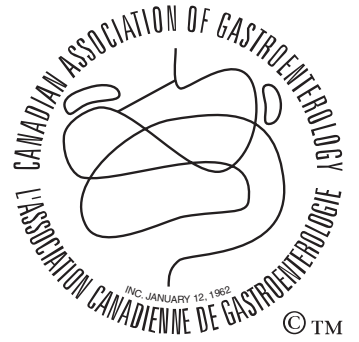

En français voir page 388

Derek McKay PhD

Chair, CAG Research Committee

$\mathrm{T}$ he mandate of the Canadian Association of Gastroenterology (CAG) Research Committee is to build, in collaboration with industry partners and the Canadian Institutes of Health Research (CIHR), Canadian capacity and expertise in the discipline of gastroenterology and nutrition and to promote excellence in research. Having completed one year of a three-year term as chair of the Research Committee, it is a pleasure to update the CAG membership (and The Canadian Journal of Gastroenterology readership) on the activities of the Research Committee (2002-2003), in what has been an outstanding year for investment in gastrointestinal research in Canada.

First, I gratefully acknowledge the efforts of the Research Committee (Table 1), Mr Paul Sinclair, the CAG National Executive Director, and Ms Sandra Daniels, Manager, CAG, for their participation in and commitment to the research activities of the CAG. I would also take this opportunity to thank Dr Herbert Gaisano (University of Toronto) who completed his term as committee member (2000 to 2003) and to welcome Dr Young-In Kim (University of Toronto), Dr Jon Meddings (University of Calgary) and Dr Linda Yu (postdoctoral fellow representative, University of Calgary) as new members of the CAG Research Committee, effective as of February 2003.

Details relating to eligibility and application processes for all of the following awards are available at the CAG Web site $<$ www.cag-acg.org>. The review and assessment of applications complies with CIHR standards and guidelines.

CAG-CIHR-partnered postdoctoral operating fellowship programme

The fellowship programme is the cornerstone of the CAG research activities. Since 1992, approximately $\$ 8.7$ million have been invested in funding 87 postdoctoral fellows. The programme has been remarkably successful, and the details of this success will be published in an upcoming issue of The Canadian Journal of Gastroenterology. This year, 32 fellowship applications were received -24 in the regular competition, three in a special call for epidemi- ology projects and five for a Nestle Nutrition Inc partnered award for research relevant to pediatric gastroenterology (GI). With funding from CIHR, the Crohn's and Colitis Foundation of Canada (CCFC), the Canadian Digestive Health Foundation and CAG's industrial partners (see acknowledgements), we funded 18 fellowships; a $56 \%$ success rate for a total one-year investment of approximately $\$ 1,080,000$ ! See Table 2 for details on the successful applications.

\section{Fellow-to-faculty transition award}

With such a successful fellowship programme, the concern arises that lack of opportunities at the faculty level would result in loss of talented Fellows from GI research. In an effort to address this, and in partnership with CIHR, CCFC and AstraZeneca Canada Inc., two awards were offered that would provide the successful applicants, who had two to four years of postdoctoral training, with a one-year fellowship followed by two years of salary at the Assistant Professorship level and a modest operating budget, for a total award of $\$ 70,000$ per annum for each of the three years. It was deemed critical that the applicants outline a research direction independent of their postdoctoral supervisor. With a very short lead in time, four applications were received and all ranked in the excellent (or top of the very good) category. All of the applicants were worthy of funding. The successful applicants are shown in Table 3. The response and discussion around this new initiative has been gratifying and stimulating, indicative of the need and support for this type of award within the GI community. We hope to continue to attract sponsorship for this programme and firmly establish it as an integral part of the CAG research activity.

\section{CAG summer studentships}

It is also important that we nurture and encourage more junior researchers, stimulating their interest in research and attracting them to the study of enteric health and disease. In partnership with the CCFC, eight students will receive awards (salary and a small operating budget, $\$ 5000$ per award) to work in laboratories of established investigators whose interests cover many aspects of

Correspondence: Dr Derek McKay, Intestinal Disease Research Programme, McMaster University, Health Sciences Centre, Room 3N5C, 1200

Main Street West, Hamilton, Ontario L8N 325. Telephone 905-525-9140 ext 22588, fax 905-522-3454, e-mail mckayd@mcmaster.ca

The CAG is proud to acknowledge its Benefactor Corporate Sponsors:
Abbott Laboratories Ltd.
AstraZeneca Canada Inc.
Axcan Pharma Inc.
Janssen-Ortho Inc. 
TABLE 1

Composition of the Canadian Association of Gastroenterology Research Committee (2003)

\begin{tabular}{lcc}
\hline Member & Institution & Term \\
\hline Derek M McKay (PhD) (Chair) & McMaster University, Hamilton, Ontario & $2002-2005$ \\
Jon Meddings (MD) & University of Calgary, Calgary, Aberta & $2003-2006$ \\
Andrew Stadnyk (PhD) & Dalhousie University, Halifax, Nova Scotia & $2003-2006$ \\
Young-In Kim (MD, PhD) & Univerisity of Toronto, Toronto, Ontario & $2003-2006$ \\
David Armstrong (MD) & McMaster University, Hamilton, Ontario & $2002-2005$ \\
Marc Deschênes (MD) & McGill University, Montreal, Quebec & $2002-2005$ \\
Johane Allard (MD) & University of Toronto, Toronto, Ontario & $2002-2005$ \\
Jean-Francois Beaulieu (PhD) & University of Sherbrooke, Sherbrooke, Quebec \\
William Paterson (MD) & Queen's University, Kingston, Ontario & $2001-2004$ \\
Alison Buchan (PhD) & University of British Columbia, Vancouver, British Columbia & $2001-2004$ \\
Kris Chadee (PhD) & McGill University, Montreal, Quebec & $2000-2004$ \\
Linda Yu (PhD) & University of Calgary , Calgary, Alberta & $2000-2004$ \\
Stephen Vanner (MD) & Queen's Universityt, Kingston, Ontario & $2003-2005$ \\
\hline
\end{tabular}

"Postdoctoral fellow representative; Representative of the Canadian Digestive Health Foundation

\section{TABLE 2}

Canadian Association of Gastroenterology-Canadian Institutes of Health research-partner funded postdoctoral fellowships (July 2003)

\begin{tabular}{|c|c|c|c|c|}
\hline Candidate & Industrial Partner & Years & Institution & Supervisor(s) \\
\hline Eduardo da Silveira & ALTANA Pharma Inc & 2 & McGill University, Montreal, Quebec & A Barkun \\
\hline Elena Verdu & AstraZeneca Canada Inc & $2(+1)$ & McMaster University, Hamilton, Ontario & S M Collins \\
\hline Graciela Andonegui & AstraZeneca Canada Inc & $2(+1)$ & University of Calgary, Calgary, Alberta & P Kubes \\
\hline Peter Suenaert & AstraZeneca Canada Inc & $2(+1)$ & McGill University, Montreal, Quebec & G Wild \\
\hline Rafael Perini & AstraZeneca Canada Inc & $2(+1)$ & University of Calgary, Calgary, Alberta & JL Wallace \\
\hline Tara Nixon-Chalmers & AstraZeneca Canada Inc & $2(+1)$ & University of Alberta, Edmonton, Alberta & K Madsen, R Fedorak \\
\hline Fernand-Pierre Gendron & Axcan Pharma Inc & 2 & University of Sherbrooke, Sherbrooke, Quebec & N Rivard \\
\hline Alex Chin & Axcan Pharma Inc & 2 & Emory University, Atlanta, Georgia, USA & C Parkos, A Nusrat \\
\hline Wei Qi & CCFC & $1(+1)$ & University of Calgary, Calgary, Alberta & DM McCafferty \\
\hline Yang Li & CCFC & $1(+1)$ & University of Calgary, Calgary, Alberta & S Lee \\
\hline Mehri Zareie & Ferring Pharmaceuticals & 1 & Hospital for Sick Children, Toronto, Ontario & PM Sherman \\
\hline Yan He & Jansen-Ortho Inc & 2 & University of Toronto, Toronto, Ontario & H Gaisano \\
\hline Stella Zamuner & Jansen-Ortho Inc & 2 & University of Calgary, Calgary, Alberta & JL Wallace \\
\hline Maureen Ajuebor & Schering Can. Inc & 1 & University of Calgary, Calgary, Alberta & M Swain \\
\hline Samara Freeman & Solvay Pharma Inc & 2 & University of California, California, USA & H Raybould \\
\hline Lawrence Hookey & Solvay Pharma Inc & 2 & Queen's University, Kingston, Ontario & W Depew \\
\hline Teresa Longobardi & AstraZeneca/CDHF & 2 & University of Manitoba, Winnipeg, Manitoba & P Jacobs, C Bernstein \\
\hline Diana Mager & Nestle Nutrition Inc & 2 & University of Toronto, Toronto, Ontario & E Roberts \\
\hline
\end{tabular}

CCFC Crohn s and Colitis Foundation of Canada; CDHF Canadian Digestive Health Foundation

gut function (Table 4). Eighteen applications were reviewed giving an approximately $44 \%$ success rate in this year's competition.

Operating grants

Dr Carole Creuzenet from the University of Western Ontario (London, Ontario) successfully renewed the second year of her award for her project 'Functional and clinical investigation of two new genes involved in the control of the virulence of Helicobacter pylori' (industrial partner: Abbott Laboratories Ltd).

No new grants were awarded in 2003. No applications for the New Investigator Award were received.

Congratulations are extended to all the successful awardees. We look forward to your participation in Canadian GI research and the results of your labours. Well done!

\section{Canadian Digestive Diseases Week 2003}

The Canadian Digestive Diseases Week (CDDW) conference showcases the Canadian GI research community. Approximately 300 abstracts were submitted to the core scientific programme, and 210 of these were accepted for presentation: 12 as oral presen- tations and the remainder as posters, presented over the three days of the scientific meeting. Scientific symposia were presented on 1) the innate immune response in the intestine (chaired by Drs A Buchan, University of British Columbia, Vancouver, British Columbia and D Podolsky, Harvard University, Boston, Massachussetts, USA); and 2) the enteric nervous system and sensation in the gut (chaired by Drs W Paterson, Queen's University, Kingston, Ontario and G Tougas, McMaster University, Hamilton, Ontario). A workshop entitled 'Transition from trainee-to-faculty' was organized and chaired by Drs WK MacNaughton (University of Calgary) and DM McKay (McMaster University), in which sessions on paper writing, interview technique and grant writing were presented. The workshop was well attended and attendees suggested that a similar event be held at CDDW 2004.

The following are the 2003 recipients of CAG awards:

- Dr Daniel Ménard (University of Sherbrooke, Sherbrooke, Quebec) Research Excellence Award Lecturer 
TABLE 3

Successful applicants in the first Fellow-Faculty Transition Award competition (effective July, 2003)

\begin{tabular}{lccc}
\hline Fellow & Partner & Institution & Supervisor (first year only) \\
\hline M Sewitch & AstraZeneca Canada Inc. & McGill University, Montreal, Quebec & A Barkun \\
W Khan & CCFC & McMaster University, Hamilton, Ontario & SM Collins \\
\hline
\end{tabular}

CCFC Crohn s and Colitis Foundation of Canada

\section{TABLE 4}

Canadian Association of Gastroenterology (CAG)-Crohn s and Colitis Foundation of Canada (CCFC) funded summer studentships (2003)

\begin{tabular}{lcc}
\hline Candidate & Sponsor & Institution \\
\hline Mr R Noor & CCFC & Queen's University, Kingston, Ontario \\
Mr J Rullo & CCFC & McMaster University, Hamilton, Ontario \\
Ms L Youden & CCFC & Dalhousie University, Halifax, Nova Scotia. \\
Mr E Ho & CCFC & McMaster University, Hamilton, Ontario \\
Mr M Peplowski & CAG & University of Calgary, Calgary, Alberta \\
Ms M Briggs & CAG & Queen's University, Kingston, Ontario \\
Ms A-M Pelletier & CAG & Queen's University, Kingston, Ontario \\
Mr P Lam & CAG & University of Toronto, Toronto, Ontario \\
\hline
\end{tabular}

- Dr Young-In Kim (University of Toronto) Young Investigator Award Lecturer

- Dr Keith Sharkey (University of Calgary) Visiting Professor

- Dr Claude Roy (University of Montreal) Education Excellence Award Lecturer

- Dr David Whitcomb (University of Pittsburgh, Pittsburgh, Pennsylvania) Kopelman Award Lecturer

- Dr Micheline Ste-Marie (McGill University, Montreal, Quebec) Distinguished Service Award

- Dr Kim E Barrett (University of California, San Diego, California, USA) The R.D. McKenna Memorial Lecturer

- Dr Donald Weaver (Dalhousie University, Halifax, Nova Scotia) State of the Art Lecturer

Student prizes for the outstanding quality of their abstracts were awarded to Mr A Chin (University of Calgary), Ms C Green (McMaster University), Mr R Joseph (Dalhousie University), and Ms MM Hunter (McMaster University). These awards were sponsored by the CAG and the CCFC, and Mr Michael Howorth, the National Director of the CCFC, presented two of the awards.

All of these awards, along with the 18 fellowships and the two Fellow-to-Faculty awards, were presented at an awards ceremony at CDDW. This event was open to all conference delegates, with supervisors and representatives from the sponsoring partners attending to present the awards and for photograph opportunities.

\section{Workshops}

Sponsorships of $\$ 5000$ were allotted to Dr J Wallace and Dr K Sharkey (University of Calgary) for scientific meetings which they organized in 2003, the 'Banff Inflammation Workshop' (February 2003) and 'The Enteric Nervous System' (July 2003), respectively. These funds are to offset some of the costs incurred by CAG trainee members who attend the conferences.

\section{Directions}

The CAG is committed to funding excellent research and has in place a number of programmes to support both $\mathrm{MD}$ and $\mathrm{PhD}$ scientists. Outstanding progress has been made in funding talented fellows, but under-funding of gastroenterological-related research in Canada remains an issue. Thus, it is imperative that we continue to attract funding to support talented trainees, at all levels, and to be creative in developing new funding opportunities for junior and established GI researchers, both the purist and those more focused on mutli-disciplinary research strategies. Such goals will only be achieved by cooperative interaction with, and the continued support of, our pharmaceutical industrial partners, the CIHR, the CCFC and the Canadian Digestive Health Foundation. Indeed, to that end, considerable effort has been invested in developing a formalized Cooperative Agreement with CIHR (Research and Development), a document that is nearing completion and may be in place for July 2003.

The Research Committee and I will strive to maintain the level of excellence that already exists in our funding programmes and will continue to work on our partnership agreements; funding opportunity for $\mathrm{PhD}$ students; stimulating interactions between the GI community and other disciplines; and highlighting the CDDW as a first class GI research meeting where Canadian collegiality is at the forefront.

Should CAG members have questions relating to the activities of the Research Committee or ideas on how to expand upon our activities please contact either myself or any of the committee members (Table 1).

ACKNOWLEDGMENTS: Past and present funding from the following is gratefully acknowledged: Canadian Institutes of Health Research, Abbott Laboratories Ltd, ALTANTA Pharma Inc, AstraZeneca Canada Inc, Axcan Pharma Inc, Carsen Group Inc, Crohn's and Colitis Foundation of Canada, Canadian Digestive Health Foundation, Ferring Pharmaceuticals, GlaxoSmithKline, Janssen-Ortho Inc, Nestle Nutrition Inc, Novartis and Bristol Myers Squibb, Schering Canada Inc and Solvay Pharma Inc. 


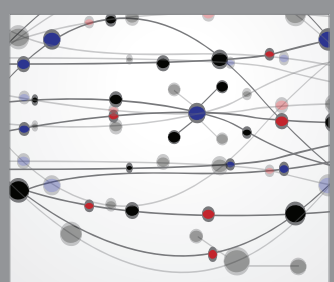

The Scientific World Journal
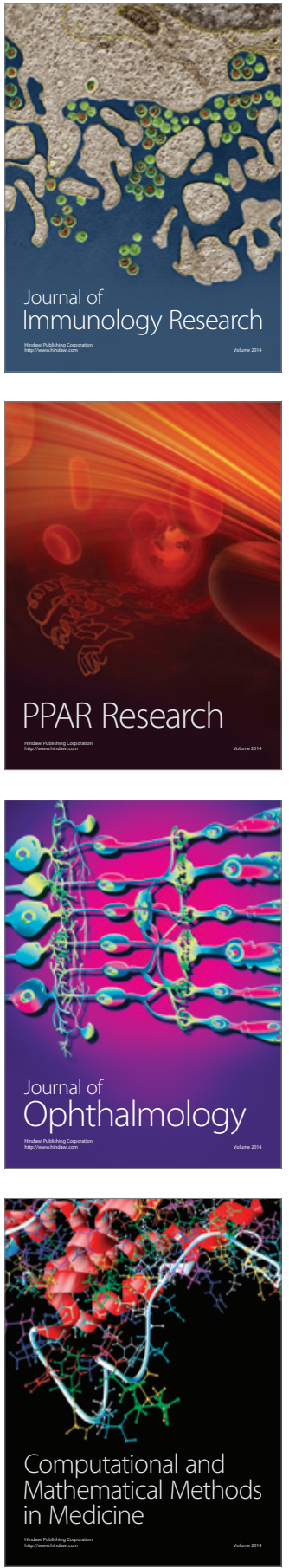

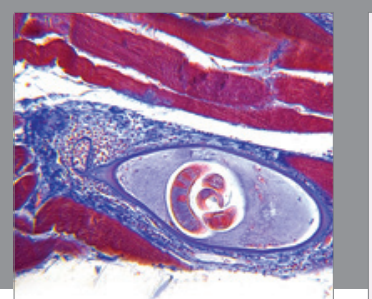

Gastroenterology Research and Practice

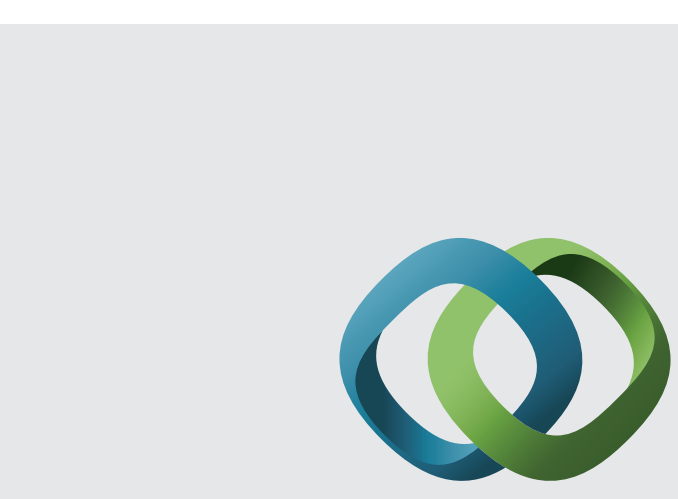

\section{Hindawi}

Submit your manuscripts at

http://www.hindawi.com
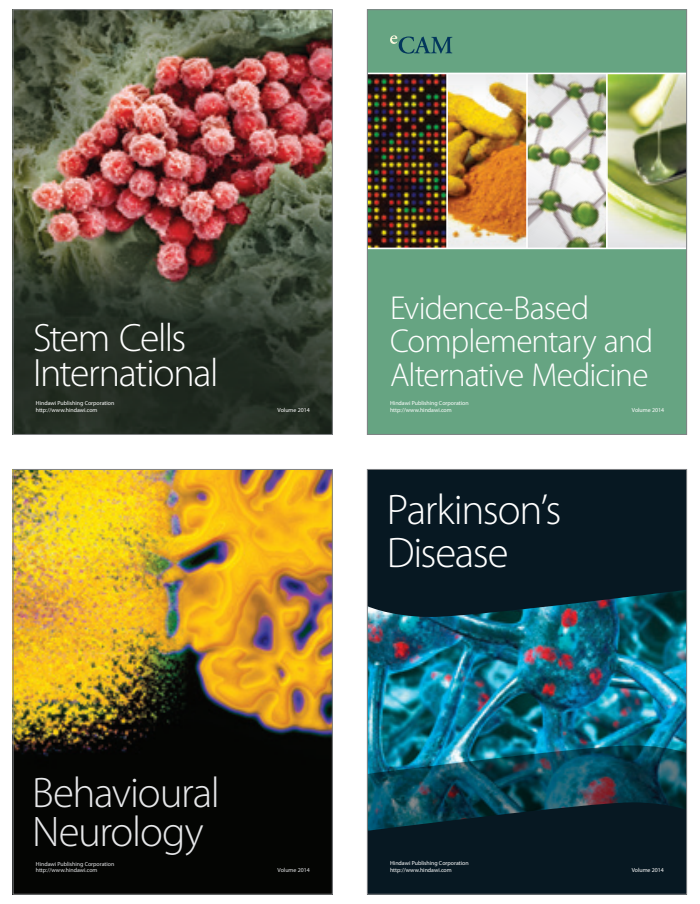
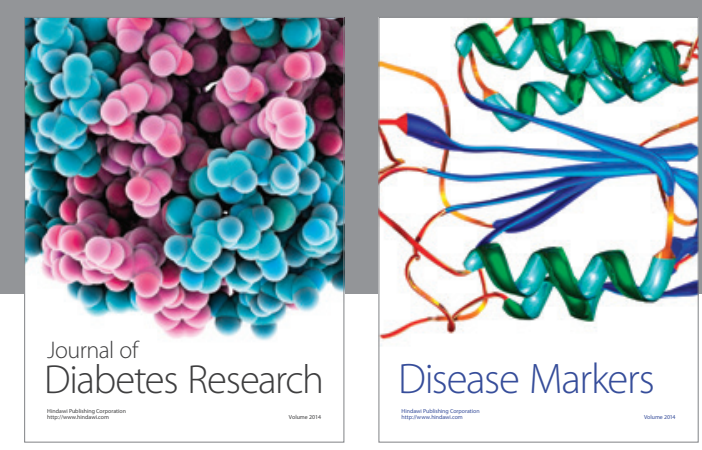

Disease Markers
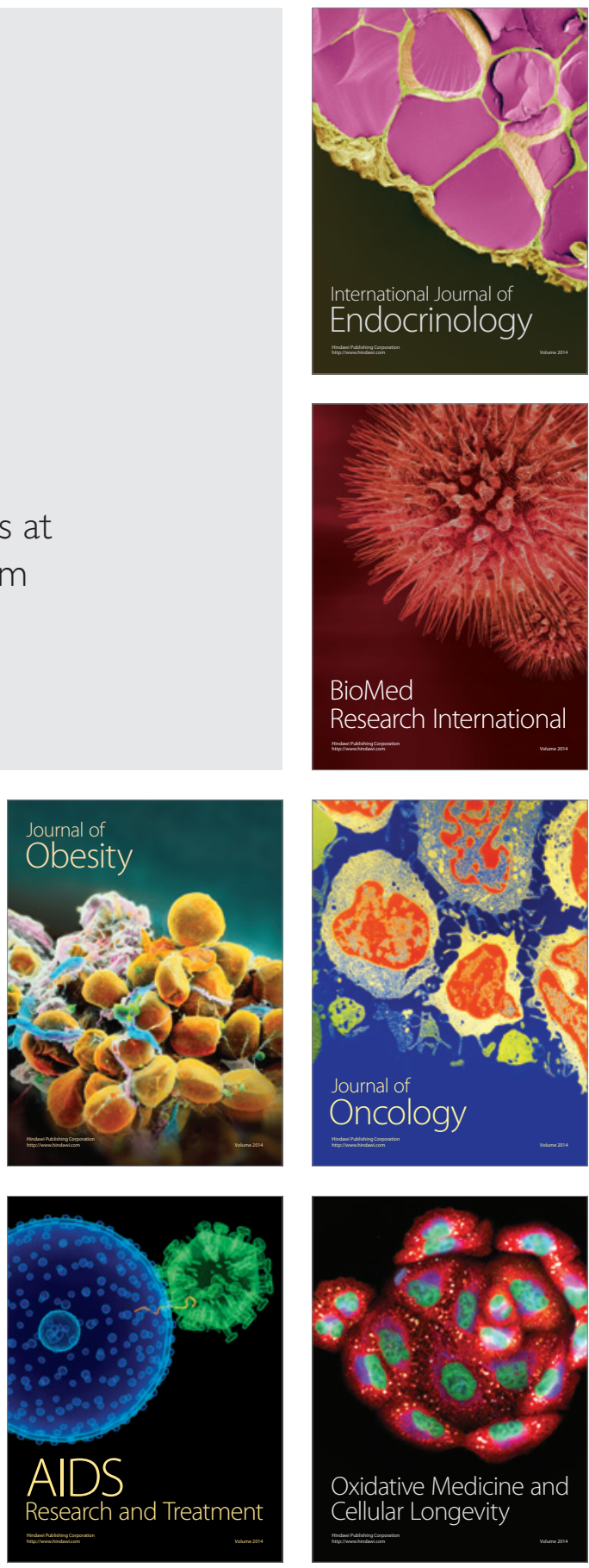